
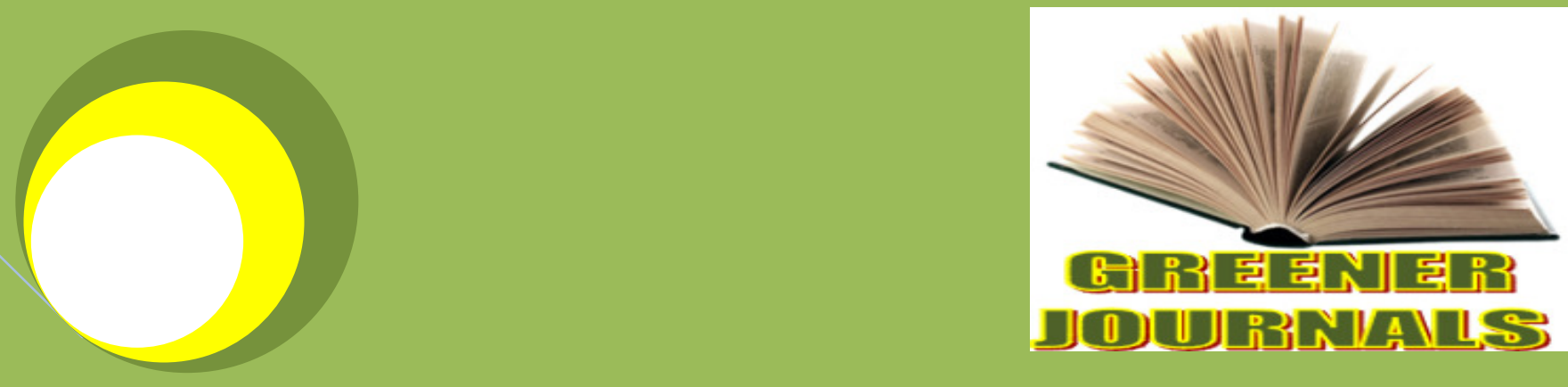

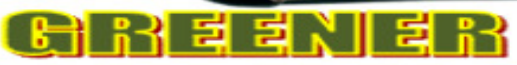
D(0) (1)

Greener Lournal lof Plant Breeding and Crop Science ISSN: 2354-2292

Stability Analysis of Bean Yields of Arabica Coffee Genotypes across Different Environments

By

Yonas Belete Bayetta Belachew Chemeda Fininsa

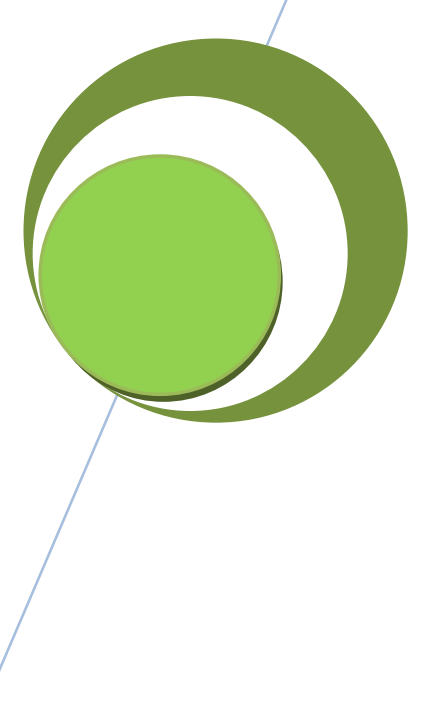




\title{
Stability Analysis of Bean Yields of Arabica Coffee Genotypes across Different Environments
}

\section{Yonas Belete $^{\star 1}$, Bayetta Belachew ${ }^{2}$, Chemeda Fininsa ${ }^{3}$}

\author{
${ }^{1}$ Plant Breeder, Jimma Agricultural Research Center, P.O. Box, 192, Jimma, Ethiopia. \\ ${ }^{2}$ Plant Breeder, Inter Africa Coffee Organization (IACO) Research Director. \\ ${ }^{3}$ Plant Pathologist, Associate Professor, Haramaya University, P.O. Box 138, Dire Dawa, Ethiopia. \\ *Corresponding Author's Email: yonasbelete85@yahoo.com
}

\begin{abstract}
An evaluation of stability of thirty Arabica coffee genotypes was carried out across different environments. The interaction of genotype by environment $(G \times E)$ across the different environments was highly significant. Both heterogeneity of regression and pooled deviation mean square from regression were highly significant. On this basis stability analysis was done using regression and AMMI models. On the basis of the analyses, different sets of genotypes were found as stable by the two models. Genotypes $7803 \mathrm{~A}$ and $7803 \mathrm{~B}$, which were at the $13^{\text {th }}$ and $14^{\text {th }}$ ranks from thirty genotypes, were found as stable by the regression model. On the other hand genotypes 8143, 75187B and 8019, which were at the second, third and seventh ranks, were found as stable by the AMMI model. The discrepancy noticed in the two models in indicating the stable genotypes was largely attributed to their differences in accounting the interaction sum of squares. The result of the study is considered as one remarkable success in the history of Arabica coffee research as identifying stable genotype for multi-locations / diverse environments has long been a major challenge and in practice able for decades.
\end{abstract}

Keywords: Stable, Genotype, Arabica coffee, Environments.

\section{INTRODUCTION}

Arabica coffee is avital crop in the national economy of Ethiopia. Substantial proportion of the people in the country one way or the other earns their livelihood from coffee production or its trade. The country used to fetch up to $65 \%$ of its foreign currency from coffee export until very recently (Vander, 1981; Vander, 1997). Even now after the incoming of many exportable commodities the share that comes from coffee still constitutes $40 \%$ of the national export (Behailu et al., 2008; Nigussie et al., 2008). The land covered with coffee in Ethiopia is also very substantial and is estimated to range from 400,000 to 650,000 hectares, the average being 550,000.

Despite coffee plays dominant role in the national economy and in spite of the fact that the country is home of arabica coffee, the country's coffee industry is characterized by low productivity. The factors attributed to such threat could be lack of resistant varieties to diseases and insect pests and poor agronomic practices (Eshetu, 1997; Eshetu et al., 1999; Workafes and Kassu, 1999). Lack of suitable varieties that exhibit stable performance across wide ranges of environments is one from the major factors attributed to low productivity of Arabica coffee (yonas and Bayetta, 2008). The national average yield per hectare as judged from the total land coverage has not exceeded six quintals. In an attempt to increase productivity and production of coffee using stable varieties, Mesfin and Bayetta (1987) carried out adaptation tests across different environments. The result of their study confirms the fact that varieties that exhibit better adaptation at one location in one coffee growing region do not perform well at other locations of a different geographic region. This was further proved from the poor adaptation of the coffee berry disease resistant (CBD) varieties released for south-western Ethiopia when grown at the Eastern geographic region of the country (Mesfin, unpublished). Same varieties also fail to exhibit wide adaptation at the major coffee growing environments even within south-western region other than the fertile forest soils where they evolved at (Vande, 1997). The failure of the genotypes to exhibit wide adaptation across wide environments is largely attributed to the fact that they were developed and released for their resistance to coffee berry disease and no extensive adaptation tests were carried out earlier across wide environments before release. Adaptation tests carried out elsewhere in other countries also confirms the presence of significant interaction effect of genotypic performance across different environments (Agwanda and Owuor, 1989; Agwanda et al., 1997; Montagnon et al., 2000). However, these workers reported that it is possible to identify stable varieties and minimize risk of crop failure that could result from genotype 
by environment interactions. Since Ethiopia has both wide genetic diversity of arabica coffee and diverse environments for growing it, conducting adaptation tests across different locations within region is important to identify stable genotypes and increase productivity and production of Arabica coffee across the different environments.

Thus the objective of this study was designed to identify stable genotypes that exhibit wide adaptation across the diverse agro ecologies of south-western Ethiopia and thereby increase productivity and production of Arabica coffee.

\section{MATERIALS AND METHODS}

\subsection{Experimental Sites}

The trials were conducted at four different locations in south-western region of Ethiopia: Jimma, Agaro, Metu and Gera. The first three locations represent medium altitude; Gera represents high land and their description is given in Table 1.

\subsection{Materials}

The trials consisted of thirty pure lines Arabica coffee genotypes. They represent all the three types of canopy configuration: compact, intermediate or open. They were selected for their high potential for resistance to CBD, yield and cup quality during a preliminary evaluation at Gera. Primarily they were collected from different farmers' field of south-western region of the country along with quite large numbers of coffee accessions. The preliminary evaluation for yield and CBD resistance was done for four years at Gera. The seeds (beans), which were used for raising the seedlings, were prepared from representative bushes of each genotype. The beans were sown and raised in polythene bags for ten months. Holes were dug and filled with topsoil before planting. The seedlings were field planted when they are approximately ten months old in randomized complete block design of three replications. They were mulched in September immediately after planted. Each seedling was also protected from direct sunlight by small grass shelters starting from October until the normal rain in 2006 commenced. The shelters were removed when the normal rain after the dry months started. Sesbaniasesban (temporary shade bush) were planted to provide regular shade over the plots. Each plot consisted of ten bushes in single row. The spacing between rows and bushes within row were $2 \mathrm{~m}$ by $2 \mathrm{~m}$, respectively. The plots received uniform application of fertilizer and other cultural practices throughout the period of data collection. All coffee bushes were maintained on single stem pruning system. Yield was recorded in fresh cherry to the nearest $50 \mathrm{~g}$ from 10 bushes and converted to clean coffee bean yield in kilogram per hectare. The mean clean coffee yield of the different genotypes was used for analysis. Over the course of time, some bushes had died so that by $2008 / 9$ and $2009 / 10$ some plots no longer had full 10 bushes stand. During analysis, the yield data of the plots with missing bushes were adjusted to represent a full stand of 10 bushes. The yield at harvest was multiplied by the ratio of the number of plants at the expected full stand to the number of plants harvested. No adjustment factor was used for the missing bushes as the orchards were at their first and second bearing and yield advantage for a plot with a poor stand compared to the one with a full stand is noticed only after the fourth bearings. The test materials are presented in Table 2.

Table 1: Characteristics of the test locations

\begin{tabular}{|c|c|c|c|c|c|c|}
\hline cat & Altitude & atitud & ongitur & \multicolumn{2}{|c|}{ Temperature $\left({ }^{\circ} \mathrm{C}\right)$} & $(\mathrm{mm})$ \\
\hline & & & & Min & Max & \\
\hline Jimma & $1753 \mathrm{~m}$ & $7^{\circ} 36^{\prime} 5$ & $36^{\circ} \mathrm{E}$ & 11.5 & 26.2 & 1531.8 \\
\hline Agaro & 1600 & $7^{\circ} 9^{\prime}$ & $36.6 \mathrm{E}$ & $\mathrm{NA}$ & $\mathrm{NA}$ & NA \\
\hline Gera & $1940 \mathrm{~m}$ & $7^{0} 7$ & $36^{\circ} \mathrm{E}$ & 10.4 & 24.4 & 1878.9 \\
\hline Metu & 1550 & $8^{\circ} 33$ & $36^{\circ} \mathrm{E}$ & 12.5 & 28.6 & 1810.6 \\
\hline
\end{tabular}

$\mathrm{NA}=$ Not available 
Table2: The thirty arabica coffee genotypes evaluated at four different locations

\begin{tabular}{|l|l|l|l|}
\hline Genotype & Branch configuration & Genotype & Branch configuration \\
\hline 74191 & Intermediate & 8011 & Intermediate \\
\hline $75187-\mathrm{B}$ & Intermediate & 8017 & Intermediate \\
\hline 7453 & Compact & 8019 & Intermediate \\
\hline 74145 & Compact & 8021 & Open \\
\hline 75194 & Compact & 8112 & Intermediate \\
\hline 7512 & Compact & 8133 & Open \\
\hline 7574 & Compact & 8136 & Intermediate \\
\hline $7803-\mathrm{A}$ & Intermediate & 8143 & Compact \\
\hline $7803-\mathrm{B}$ & Intermediate & 8144 & Open \\
\hline $7809-\mathrm{B}$ & Intermediate & 827 & Open \\
\hline 802 & Intermediate & 878 & Intermediate \\
\hline 804 & Compact & 8211 & Open \\
\hline 808 & Open & 8213 & Intermediate \\
\hline 809 & Intermediate & 8219 & Compact \\
\hline 8010 & Compact & 8223 & Open \\
\hline
\end{tabular}

\subsection{Statistical analysis}

Analysis of variance was done for each environment (location-year combination). Combined analysis of variance was also done after homogeneity of error variances at the specific environments (location-year combinations) was confirmed to obtain estimates of environmental, genotypes and genotype $x$ environment interaction source of variation using Agrobase software package. Joint linear regression analysis (JRA) called heterogeneity of regression (Eberhart and Russel, 1966) was used to obtain the linear and non-linear component of GxE interaction variance.

The linear regression model is, $Y U ̈=\mu+B_{i j}+\delta_{i j}$,

Where

$Y \ddot{U}=$ is the mean of the $i^{\text {th }}$ genotype at the $j^{\text {th }}$ environment

$\mu,=$ the mean of the $i^{\text {th }}$ genotype overall environments

$\mathrm{Bj}=$ the regression coefficient that measures the response of $\mathrm{i}^{\text {th }}$ genotype to varying environment

$\delta_{i j}=$ the deviation from regression of the $i^{\text {th }}$ variety of ${ }^{\text {th }}$ environment and

$\mathrm{I}_{\mathrm{i}}=$ the environmental index obtained as the mean of all genotypes at the

$j^{\text {th }}$ environment minus the grand mean

The regression coefficient $\left(B_{\mathrm{j}}\right)$ was estimated as

$$
\begin{gathered}
B_{j}=\frac{\sum y_{i j}}{\sum I^{2} I_{j}}+\delta_{i j} \text { and the deviation from regression }\left(\mathrm{S}^{2} \mathrm{~d}_{\mathrm{i}}\right) \text { is obtained as: } \\
S^{2} d_{i}=\left[\frac{\sum \delta_{i j}}{(n-2)}\right]-\frac{S_{e}^{2}}{r} \text {, where } \frac{S_{e}^{2}}{r} \text { is the pooled error }
\end{gathered}
$$

The stability analysis was done over eight environments (4 locations over two years). The stability analysis was also employed using Ammi model to portion the GxE interaction sum of squares into interaction principal component axes (IPCA).

The AMMI model is:

YÜ $=\mu+G j+E j+\left(\sum K n V n i S n j\right)+e i j$ 
Where Yijis the yield of genotype I in environment $\mathrm{j}, \mu$ is the grand mean, Gi is the genotype mean deviation, Ej is the environment mean deviation, $\mathrm{Kn}$ is the eigen value of the PCA axis, eij is the error.

The AMMI analysis of variance summarized most of the magnitude of GxE interaction into one or few dimensions (IPCA). Interaction values of genotypes and environment for each trait on the first IPCA was retained and shown on the bj-plot graph.

\section{RESULTS AND DISCUSSION}

\subsection{Clean yield}

\subsubsection{Stability analysis using regression model of Eberhart and Russel}

After confirming the presence of significant differences among genotypes for clean coffee yield at the specific environments, combined analysis of variance was done. The combined analysis of variance revealed that the mean squares of genotypes, environments and genotype by environment interaction were highly significant (Table 3 ). The significance of interaction indicates that there is uncertainty in measuring overall performance of genotypes across different environments. Thus the interaction sum of squares was portioned in to linear and nonlinear components. The interaction sum of square accounted by the linear or heterogeneity of regression coefficient was found to be highly significant and was $48 \%$ of the total interaction (Table 4). The sum of squares accounted by the deviation /nonlinear interaction component was also equally important and accounted $52 \%$ of the interaction. Since significant part of the interaction is nonlinear in nature, stability analysis was done to identify genotypes which exhibit stable performance across the different environments.

The overall means, regression coefficients and deviation mean squares from regression of stability parameters are presented in Table 5. It is evident from the table that fourteen out of thirty genotypes exhibited above average mean yields with unity regression coefficients except 8017 and 8213 for which the regression coefficients were greater than unity. This result may indicate that majority of the genotypes had wide adaptation across the different environments. This disagrees with the earlier work of Mesfin and Bayetta (1987) on adaptation of Coffea Arabica who stated that arabica coffee is location specific in performance as they could not identify single from among the 17 varieties that exhibits wide adaptation across different locations. However, such disagreement might encounter due to differences in the diversity of environments included in the two trials as it was more diverse in the former (across different locations over different geographic regions) than the latter (across different locations within a geographic region). This may indicate that it would be difficult to identify a genotype that could exhibit wide adaptation across all sets of environments over different geographic regions. But the result of the present study at least confirmed the fact that the environments in the main coffee growing regions in Ethiopia could be sub-divided in to sub-regions within which a stable genotype that can exhibit wide adaptation across different locations within a region could be identified. Such strategy would alleviate the problem of stability in performance of Arabica coffee across the diverse environments of the country that prevails at the landscape of the major coffee growing belt in Ethiopia which is characterized by an undulating and irregular terrain features where a coffee orchard on such landscape within an area of small radius (not exceeding 0.5 square kilometers) at any one part across regions may fall on either flat land or valley bottoms or sloping land of varying degree of intensity or on an environment that is optimum or sub optimum from nutrient and/or moisture availability point of view or it may be on sloping land that receives different level of light intensities. All these disparities have different bearings on the relative performance of different coffee types and only varieties that exhibit stable performance across such environments result in stable performance. But as per the definition of stability by Eberhart and Russel (1966) a variety is stable if it satisfies the following criteria a-part from having unit regression coefficient:

1) Mean of the genotypes overall environments should exceed the general mean

2) The deviation mean square $\left(S^{2}{ }_{\text {di }}\right)$ from regression should be close to zero

In view of these guiding principles, more than eighty percent of the genotypes had significant deviation from regression $\left(\mathrm{s}_{\mathrm{d}}^{2}>0\right)$ indicating that performance of majority of the genotypes was unpredictable. Such significant deviation mean squares from regression for majority of the genotypes might arise from lower accountability of the model to account for the interaction. However, 7574, 7803A, 7803B, 8011 and 8017 showed less deviation not significantly different from zero. Of which only genotypes 7803A and 7803B had mean a little bit above the general mean at the $13^{\text {th }}$ and $14^{\text {th }}$ ranks, respectively and are the only stable genotypes.

Genotypes 8143, 75187B and 8019 were the other three superior genotypes at the second, third and $7^{\text {th }}$ rank in overall yield, respectively. These genotypes in addition to having higher mean yield had unit regression Coefficient 
suggesting that they had average response across the different environments. For countries like Ethiopia where the larger share of the coffee is produced by small-scale farmers where the environments are not well defined such genotypes may help to avoid crop failure that may arise from uncertain environmental conditions. However, their significant deviation mean squares from regression $\left(\mathrm{s}_{\mathrm{di}}^{2}\right)$ impose a restriction to use them across such environments.

Genotype 8213, the first top yielder, was one from among the group with above average yield but with coefficient of regression greater than unity. Such a genotype is very sensitive to environmental changes where it responds either miserably or favorably in units of more than one time for a unit change in environmental status. But under optimum environments or with improved crop management practices, such genotype can yield maximum (Eberhart and Russel, 1966; Dabholkar, 1992; Sharma, 1998). However, its significant deviation mean square suggests that there is some uncertainty in its overall performance. However, it was illustrated by several authors that it is a natural phenomenon that varieties which usually respond favorably at optimum environments may show such significant deviation mean square from regression (Westcott, 1986; Crossa, 1990; Sharma, 1998). Thus using such varieties irrespective of their deviation mean square may not pose much risk if used for commercial production.

No single genotype was identified from the thirty selections promoted from the earlier preliminary evaluation carried out at Gera with regression coefficient (bi) value not significantly different from zero. This implies the fact that the mild selection pressure employed at Gera (which represented a favorable environments from both edaphic as well as climate point of view) could not enabled to promote those genotypes which exhibited specific adaptation at marginal environments. This indicates as a principle that preliminary evaluation to evolve varieties for all types of target environments consisting of favorable or less favorable need to be carried out at contrasting environments so that a variety suitable for the type of environment in question could be identified easily.

Table3: Mean square of the combined analysis of variance for thirty Arabica coffee genotypes across different environments

\begin{tabular}{|l|l|l|l|l|}
\hline & \multicolumn{3}{|c|}{ Mean squares } \\
& Environments(E) & Genotypes(G) & GxE & Pooled error \\
\hline DF & 7 & 29 & 203 & 464 \\
\hline Clean yield & $156519833.6^{\star \star} \mathrm{L}$ & $5133924.1^{\star *} \mathrm{~L}$ & $1594015.7^{\star \star}$ & 268360.132 \\
\hline
\end{tabular}

${ }^{* *} \mathrm{~L},{ }^{* *}$ significant against mean square of GXE and mean square of error at 0.01 probability level.

Table4: Joint regression (GXE) analysis of variance of thirty Arabica coffee genotypes for yield across eight environments

\begin{tabular}{|l|l|l|}
\hline Source of variation & Df & $152293798.1^{* *} \mathrm{~L}$ \\
\hline Environments (E) Linear & 1 & $939391.1205^{* *} \mathrm{~L}$ \\
\hline Environments (E) in G x E & 90 & $713615.436^{* *} \mathrm{~L}$ \\
\hline Genotypes (G) & 29 & $373590.4668^{* *} \mathrm{~L}$ \\
\hline $\begin{array}{l}\text { Heterogeneity of regression (GXE } \\
\text { linear) }\end{array}$ & 29 & $189690.0891^{* *}$ \\
\hline Pooled deviation from regression & 60 & 38805.24438 \\
\hline Pooled error & 240 & \\
\hline
\end{tabular}

${ }_{* \star}^{*}$ Mean squares are significant when tested against their corresponding mean squares of deviation at .05 and .01 probability level. ${ }^{* *}=$ Are significant when tested against their corresponding mean squares of error at .05 and .01 probability levels. 
Table5: Estimates of stability parameters of clean coffee bean yield in $\mathrm{kg} /$ hectare, regression coefficient (bi) and deviation mean squares $\left(S^{2} \mathrm{di}\right)$

\begin{tabular}{|c|c|c|c|}
\hline Genotype & yield & & $\mathrm{S}^{2} \mathrm{di}$ \\
\hline 74191 & 870 & .64 & $362849^{* *}$ \\
\hline 75187B & 1355 & .61 & $756945^{\star *}$ \\
\hline 7453 & 758 & .82 & $235214^{\star *}$ \\
\hline 74145 & 971 & 1.06 & $158536^{*}$ \\
\hline 75194 & 919 & 1.16 & $421004^{\star \star}$ \\
\hline 7512 & 903 & 1.08 & $556009^{* *}$ \\
\hline 7574 & 946 & 1.36 & $490239^{* *}$ \\
\hline 7803A & 1051 & .96 & -1314 \\
\hline 7803B & 1048 & .66 & 63483 \\
\hline 7809B & 1076 & .81 & $114595^{\star}$ \\
\hline 802 & 1067 & 1.28 & $277847^{\star *}$ \\
\hline 804 & 943 & .81 & $476391^{\star \star}$ \\
\hline 808 & 1228 & 1.02 & $705330^{\star \star}$ \\
\hline 809 & 1110 & 1.03 & $112586^{\star}$ \\
\hline 8010 & 809 & .64 & $181145^{\star *}$ \\
\hline 8011 & 795 & .88 & 102163 \\
\hline 8017 & 839 & $1.75^{\star}$ & 17670 \\
\hline 8019 & 1156 & 1.00 & $1020702^{* *}$ \\
\hline 8021 & 1012 & 1.03 & 72432 \\
\hline 8112 & 1091 & 1.20 & $680006^{\star *}$ \\
\hline 8133 & 842 & .86 & $114765^{\star \star}$ \\
\hline 8136 & 992 & .98 & $353345^{\star *}$ \\
\hline 8143 & 1378 & 1.18 & $439510^{\star \star}$ \\
\hline 8144 & 1142 & 1.12 & $623718^{* *}$ \\
\hline 827 & 1008 & .75 & $110991^{* *}$ \\
\hline 828 & 1016 & 1.15 & $191436^{\star *}$ \\
\hline 8211 & 1216 & 1.24 & $1142035^{\star *}$ \\
\hline 8213 & 1633 & $1.74^{\star \star}$ & $358018^{\star *}$ \\
\hline 8219 & 1248 & 1.09 & $341952^{* *}$ \\
\hline 8223 & 946 & .91 & $375424^{* *}$ \\
\hline Mean & 1046 & & \\
\hline
\end{tabular}

\subsubsection{Stability analysis using additive main effect and multiplicative interaction(AMMI) model}

Similarly, stability performance of the genotypes was done using AMMI model to increase reliability of characterizing adaptation of genotypes across different environments. The first IPCA axis alone accounted for $36 \%$ of the total interaction sum of squares and this was $50 \%$ higher in contrast to the interaction accounted by the former regression model at only $17.24 \%$ of the interaction degree of freedom (Table 6). This was in agreement with the work of Gauch (1990; 1992) and Nachit et al. (1992).

On the bi-plot graph the horizontal axis (x-axis) shows the genotypic or environments main effect and the vertical axis (y-axis) shows genotypic or environmental IPCA score. Varieties or environments that occur almost on perpendicular line in a bi-plot graph have similar means and those that fall almost on horizontal line have similar interaction pattern. Varieties and environments with large IPCA score, either positive or negative, have higher interaction whereas Varieties or environments with IPCA score of zero or nearly zero have small interaction (Crossa et al., 1990). Moreover, genotypes and environments with similar or opposite IPCA score interact positively or negatively.

From the bi-plot (Fig.1) $73 \%$ of the genotypes had mean below the general mean. But in the regression model only $53.3 \%$ of the genotypes were below the general mean. Such disagreement in assigning genotypes to the left and right of the grand mean is a result of adjustment in which AMMI used adjusted mean. In this regard only genotypes: 75187B, 808, 8019, 8100, 8143, 8219, 8211 and 8213 exhibited above the general (grand) mean. 
Genotypes: 7803A and 7803B which were identified to be stable by the regression model on the other hand were found at the left of the general mean by the latter. Genotype 8213 exhibited high IPCA score of -28.45 (Table 7) reaffirming the earlier conclusion that such genotype should only be used at specified environments. It interacted positively at favorable environments of $\mathrm{B}, \mathrm{C}$ and $\mathrm{D}$. Genotype 75187B, which had unit regression coefficient by the regression model, exhibited high positive IPCA score of 20.37 by AMMI model. In coffee the low yield observed in environments of $E, F$ and $G$ was effect of alternate bearing behavior as the previous year's yield load at same location was very high and its higher IPCA1 score in latter and its significant deviation mean square in the former are indications of its regularity of bearing over different seasons compared to the other genotypes but not resulted from its specific adaptation to less optimum environments.

Genotypes8019 and 8143 exhibited the least IPCA score indicating that they are the most stable in performance across the different environments tested. Such genotypes also exhibited unit regression coefficient by the Eberhart and Russel stability model but were characterized as unstable simply because of their significant deviation mean square. But sometimes the regression model has limitations in assigning genotypes in stable or unstable group simply by deviation mean square as it may not always result from variety's inherent irregularity but it may arise from varieties response pattern with which it is compared (Westcott, 1986). The disagreement observed in the two models could be attributed to their differences in their accountability to the interaction sum of squares.

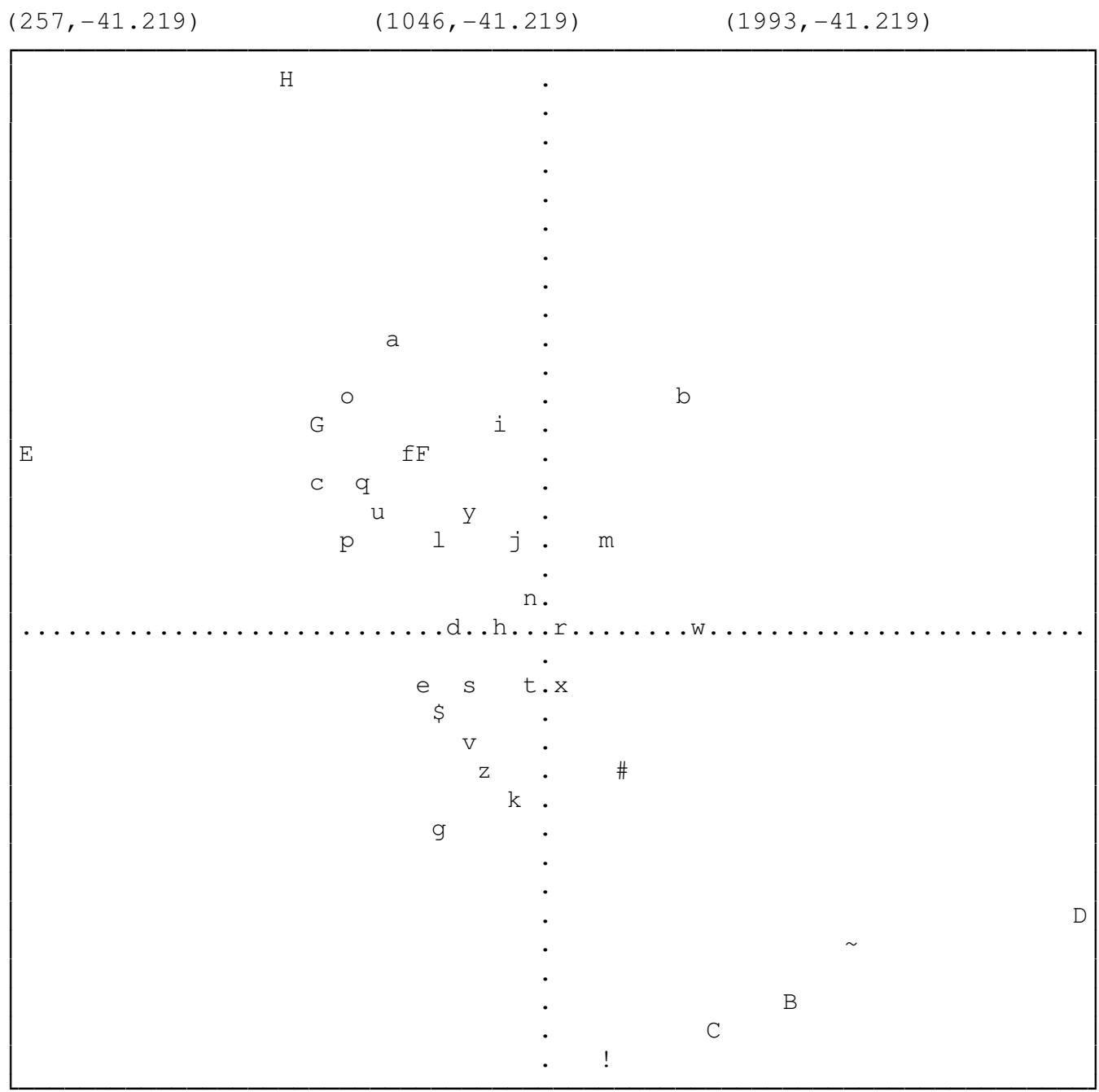

$(257,-41.219)$

$(1046,-41.219)$

$(1993,-41.219)$

Fig1: Bi-plots of genotypes in lower cases and environments in upper case for coffee bean yield using the first IPCA as ordinate and main effects as abscissa. Designations of specific genotypes and environments are based on English alphabets of lower case and upper case, respectively. Because of closer IPCA and mean grain yield performances $\mathrm{A}$ and $\mathrm{D}$ have overlapped, so $\mathrm{A}$ cannot be seen in the bi-plots. 
Table6: Mean squares of clean coffee yield from AMMI analysis

\begin{tabular}{ll}
\hline Source & Clean coffee bean yield \\
Environment (7) & $156519833.6^{\star *}$ \\
Rep within env (16) & 592788.8 \\
Genotypes (29) & $5133924.1^{\star *}$ \\
GXE (203) & $1594015.7^{\star *}$ \\
IPCA 1(35) & $3339079.5^{\star *}$ \\
Residual (464) & 268360.132 \\
\hline
\end{tabular}

Table7: Scores of genotypes and environments to the first IPCA for cherry yield

\begin{tabular}{|c|c|c|c|c|c|c|c|c|}
\hline Gen & Design & $\begin{array}{l}\text { IPCA } \\
\text { Score }\end{array}$ & Gen & Design & $\begin{array}{l}\text { IPCA } \\
\text { Score }\end{array}$ & Gen & Design & IPCA Score \\
\hline 74191 & $a$ & 24.02 & 802 & $\mathrm{~K}$ & -15.29 & 8133 & u & 9.64 \\
\hline $75187 \mathrm{~B}$ & b & 20.37 & 804 & $\mathrm{~L}$ & 6.69 & 8136 & $\mathrm{v}$ & -10.02 \\
\hline 7453 & C & 11.34 & 808 & $M$ & 7.5 & 8143 & w & -1.59 \\
\hline 74145 & $d$ & -1.6 & 809 & $\mathrm{~N}$ & 2.17 & 8144 & $\mathrm{x}$ & -4.51 \\
\hline 75194 & e & -5.84 & 8010 & $\mathrm{O}$ & 21.14 & 827 & $y$ & 8.96 \\
\hline 7512 & $f$ & 13.86 & 8011 & $\mathrm{P}$ & 8.42 & 828 & z & -12.06 \\
\hline 7574 & g & -17.61 & 8017 & Q & 11.84 & 8211 & $!$ & -41.22 \\
\hline $7803 \mathrm{~A}$ & $\mathrm{~h}$ & -1.36 & 8019 & $\mathrm{R}$ & -0.08 & 8213 & $\sim$ & -28.45 \\
\hline 7803B & I & 17.28 & 8021 & S & -4.79 & 8219 & $\#$ & -12.53 \\
\hline $7809 B$ & j & 7.5 & 8112 & $\mathrm{~T}$ & -5.84 & 8223 & $\$$ & -7.93 \\
\hline \multicolumn{9}{|c|}{ Environments } \\
\hline Jimma1 & A & 0.4 & Gera1 & C & -36.58 & Jimma 2 & $E$ & 14.55 \\
\hline Agaro1 & B & -34.54 & Metu1 & $\mathrm{D}$ & -25.01 & Agaro 2 & $\mathrm{~F}$ & 14.55 \\
\hline Gera 2 & G & 18.28 & Metu 2 & $\mathrm{H}$ & 48.19 & & & \\
\hline
\end{tabular}

Abreviations: Gen $=$ Genotype, Design $=$ Designation, Jimma 1 = Jimma at year one, Jimma 2 $=$ Jimma at year two, Agaro 1= Agaro at year one, Agaro 2 = Agaro at year two, Gera 1= Gera at year one, Gera 2= Gera at year two, Metu 1= Metu at year one, Metu 2= Metu at year two

\section{SUMMARY AND CONCLUSIONS}

The major coffee growing environments in Ethiopia are vast and contrasting that developing same varieties to use across such environments has not been possible to maximize productivity and production of Arabica coffee for decades. However, the result of this study illustrated the fact that by sub dividing the target populations of coffee growing environments in the country into sub regions genotypes that could exhibit stable performance across the different locations in a region could be identified. Therefore independent variety development program should be adopted as a right strategy to develop varieties for two regions which are extremely contrasting.

Since both the linear and non-linear parts of the interaction in a genotype -environment system across the different locations in different regions are significant, interaction of genotypes can be avoided if either specific varieties are developed for each defined environment by sub dividing the environments in the different regions into sub eco types or developing stable varieties that exhibit wide adaptation if the environments in the system are not well defined. Therefore, both types of varieties should be developed as a strategy to maximize overall production and productivity of Arabica coffee across the different regions in the country.

In the comparison between the two models employed in this particular study, interaction sum of squares recovered by the AMMI model was higher than the regression and this was the reason for the latter to be more efficient in identifying the most superior stable genotypes than the latter. This in general indicates that analysis of adaptation of genotypes in multiple models is helpful to increase reliability of characterization adaptation of varieties across different environments. 


\section{REFERENCES}

Agwanda, C.D., Baradat, P.C., and Charrier, A., 1997. Genotype by Environment Interaction and its Implication. In: XvlleColloqueScintifique International due café Nairobi (Kenya). 7: 20 -25 Asic Paris 424-429

Agwanda, C.O.J., Owuor, J.B.O., 1989. Clonal Comparative Trials in Arabica Coffee (Coffeaarabica L.) I, In: The effect of broadening the genetic base on the stability of yield in Kenya. Kenyan coffee. 54: 639-642.

Behailu, W., Abrar, S., Nigussie, M and Solomon, E. 2008. Coffee processing and quality research in Ethiopia. In the proceedings of Coffee diversity and Knowledge Workshop EIAR, Addis Abeba, P. 345-356

Crossa, J., Gauch, H.G. and Zobel, R.W., 1990. Additive main effect and multiplicative interaction analysis of two international maize genotypes trials. Crop Sci., 30:493-500.

Crossa, J., 1990. Statistical analysis of multi-location trials. Advances in agronomy. 44: 55-85

Dabholkar, A.R., 1992. Genotype x environment interaction and stability parameters. In:Elements of biomaterial genetics. International publisher, New Delhi.

Eberhart, S.A. and Russel, W.S., 1966. Stability parameters for comparing varieties. Crop. Sci. 6: 36-40.

Eshetu, D., 1997. Coffee disease and their significance in Ethiopia. Asic 17 ${ }^{\text {th }}$ Kenya, Nairobi. VI, Pp723-26.

Eshetu, D.,Teame G. and Girma A., 1999. Significance of Minor disease of CoffeaarabicaL. In Ethiopia: A review (Pp58-65)

Gauch, H.G. Jr., 1990. Matmodel version II AMMI and related analyses for two-way data matrices. Microcomputer power, Ithaca.

Gauch, H.G.Jr., 1992. Statiscal analysis of regional yield trials. AMMI analysis of factorial designs. Elsevier, Amsterdam.

Mesfin, A and Bayetta, B., 1987. Genotype- environment interaction in coffee, Coffeaarabica L. (submitted to EJAS for publication)

Montangnon, Christophe, CilaschristianleoryAntoine, yapo Antoine and Charmentant Pierre, 2000. Genotype-location interaction for coffee canephora yield in Ivory Coast. Agronomic 20:101-109

Nachit, M..N., G. Nachit, H. Ketata, Gauch, H.G.Jr., Zobel, R.W., 1992. Use of AMMI and regression models to analyze genotype environment interaction in durum wheat. Theor. Appl. Genet. 83:597-601

Nigussie, E. Deresse, T., Berhanu, M., and Getachew, W. 2008. Research Center Based Extension Intervention on Improved Coffee Technologies. In the proceedings of Coffee diversity and Knowledge Workshop EIAR, Addis Abeba, P. 345-356

Sharma, J.R., 1998. Statistical and Biometrical Techniques in plant breeding. New age, age international publishers, New Delhi, 432P

Van der graaf, N.A., 1981. Selection of arabica coffee types resistance to CBD in Ethiopia. Doctoral thesis. Mededlingenlandbouwhoge school, Wageningen, the Netherlands. Ilo pp.

Vander Vossen, H.A.M, 1997. Quality aspects in arabica coffee breeding programs in Africa.Asic $17^{\mathrm{e}}$ international scientific colloquium on coffee, Nairobi, Kenya.

Westcott, B. (1986). Some methods of analyzing genotype-environment interaction. Heredity 56, 243-253.Workafes, W., and Kassu, K., 1999.Coffee production system in Ethiopia. In the Proceedings of Coffee diversity and

Knowledge Workshop EIAR, Addis Abeba, P.99-106.

Yonas, B. and Bayetta, B., (2008). Genotype by environment interaction and stability analysis of Arabica genotypes. Proceedings of Coffee Diversity and Knowledge Workshop EIAR, Addis Abeba, P. 58-63. 